\title{
Chinese Social Orientation in the Preference of Translation Work's Choices
}

\author{
Qi $\mathrm{CHEN}^{1, \mathrm{a},{ }^{\star}}$ \\ ${ }^{1}$ Chengdu University of Information Technology, China \\ acq23237@163.com
}

\begin{abstract}
Keywords: Chinese Social Orientation, Translation Work, Preference.
\end{abstract}
\begin{abstract}
The paper analyses the preference of translation work's choices according to Yang. K. S.'s Chinese social orientation theory. A questionnaire on the basis of family orientation, relationship orientation, authority orientation and others orientation were designed and 100 sophomores at a university were invited to answer it. The investigation shows when choosing the suitable work to translate, Chinese translators consider many elements relating to Chinese social orientation, except their own ideas. Although there are exceptions, most of the key points in Chinese social orientation theory can be discovered in the answers of the respondents. The influence of Chinese social orientation to translators is valuable in translation study.
\end{abstract}

\section{Introduction}

Chinese value orientation is one of the hottest topics in the study of Chinese social psychology. Scholars coming from various fields have various opinions about it. Fei Xiaotong [1] considers egoism is Chinese people's key value. Qian Mu [2] believes harmonious integration is the key part, emphasizing the harmonious situation among people and between people and nature, and the cooperation in a group. Yu Yingshi [3] thinks personalism, not individualism, is the core. In Weber's [4] opinion, Confucian mentality is the character of Chinese people's value. Although Riseman [5] believes that Chinese society belongs to the type of tradition-directed society, some scholars such as Parson, T. \&White, W. [6], Hsu, F. L. K.[7] think that it belongs to the type of other-directed society. Triandis [8, 9] mentions that Chinese value orientation is collectivism. No matter what kind of value orientations scholars mention, social element is one of the unavoidable elements in Chinese value orientation.

Yang. K. S. [10] first mentioned his Chinese social orientation theory in 1981. In his opinion, the character of Chinese behavior can be concluded into social orientation which is a kind of behavior orientation and means Chinese people are easy to show deference to others, conform to others' expectations and concern too much about others' opinion. About eleven years later, he improved his own theory. His new Chinese social orientation includes four parts: family orientation, relationship orientation, authority orientation and others orientation. [11]

David Block considers "linguistics, and any study associated with language, serves social analysis" [12]. Language "is the bridge and mirror for people to learn or understand cultural value orientations" [13]. Language can have an influence on value orientation, and vice-versa. Chinese social orientation has an influence on language translation and guides translators' thoughts and actions to some degree. [14] The translators here do not mean those professional translators but mean all the people who do translation work. The author tries to design a questionnaire according to Yang's four social orientations in order to observe the Chinese translators' activities. 


\section{Research Methods and Procedures}

Chinese translators' activities include several phrases. The translation work's choosing, understanding, expressing, checking and publishing can be found out in the translation process. In this paper, the author only discusses the translation work's choosing.

According to Yang's opinion, there are several central points in each orientation. Continuation, harmony, unity, prosperity, honor and familization are listed in family orientation; formalization, interdependence, harmony, fatalism and determinism in relationship orientation; sensitivity, worship and dependence in authority orientation; scruple, deference, norms and reputation in others orientation.[11] Except for some irrelevant points such as continuation, fatalism, the author designed 40 questions by using those central points and invited 20 students who did not take part in the later investigation to answer. Then, the author selected their answers as the options in a questionnaire according to the repetition rate and cut off some useless questions. Thirty issues about the preference in translation works' choices were involved in the questionnaire at last. For each Chinese social orientation, 7 to 8 issues were included.

The samples are students having some translation experiences. 100 sophomores at a university whose majors are not English were randomly selected out and answered the questionnaire. Two reasons made the sophomores chosen. Firstly, unlike English majors and the juniors and seniors of non-English majors, they knew little about translation theories and the teachers explained not too many their own ideas about translation to the students. So the translation theories and their teachers' ideas cannot have a great influence on them. They can more likely do the judgments according to their true nature. Secondly, unlike the freshmen whose majors are not English, they have already had some experience in article translation. It helps them understand and finish the questionnaire. Many students in high schools do little article translation in China. But in order to pass the CET 4 and 6 in which there are paragraph translations, they tried to improve their translation ability and did some exercises of article translation in their freshman year.

\section{Results Analysis and Discussion}

\section{About Family Orientation}

In the questionnaire, $96 \%$ of the respondents thought that they would think over their choice of translation work if their families or relatives objected it. 68\% would obey families' opinion and give up their choices, because it was not very important things and they know their families' opinion was for their own good. But $72 \%$ of them confessed they would insist on their own choices of translation work at last if they really believed what they did. From the data, people want to have a harmonious relationship with the families and relatives. The pursuit of harmony, a key in family orientation, plays an important role. Harmony is one of the mainstream traditional values in China. [15] "Families satisfy their physical and psychological needs in order to maintain the family and to survive as a group.'[16] So people will try to satisfy the families' and relatives' psychological needs and avoid conflicts especially in the non-core points and keep the unity of family. But the data also shows that when people have enough confidence to their choices, about 2/3 of them will not change their mind. And it may be the embodiment of the individual in a group.

$74 \%$ of respondents said they usually did not choose the work to translate if its author was unfriendly to China, even if they liked it. But if the content of the author's work 
was benefit for national development, $86 \%$ of them would be willing to translate. That's to say, most of them did their selection of translation work on the basis of national interest and put their own hobbies and interests in the secondary position. Family is the basic unit and the core group of living in Chinese society, whose members always try their best to safeguard its reputation and benefit for the maintainance and development under family orientation. Family and country are inseparable to Chinese people. [17] When they expand the feelings and ways of dealing with affairs into country, people will try to safeguard the national reputation and benefit as they do for the family. If the individual benefit conflicts with the national, many people will obey the country's need. Yang called it as a kind of familization process.

\section{About Relationship Orientation}

$82 \%$ of the respondents said that if their choice of translation work conflicted with the choice of boss in the company, they would obey the boss's idea firstly. When the boss was changed into the English teacher, $69 \%$ would obey the teacher's choice. When the boss was changed into a big-shot scholar in translation, $75 \%$ would obey the big-shot scholar's. $83 \%$ agreed that the social relationship between employer and employee, between teacher and student, and between big-shot scholar and ordinary people was one of the most important reasons why they would follow others' suggestion and change their own ideas in the choices of translation work. It shows that people emphasize the importance of social role which is decided by the relationship of Chinese society and would like to limit their behavior according to their own roles in the society. The setting and fixing of social roles is a kind of formalization in relationship orientation. Just like Hsu said, Chinese people focus on their social position and always try to let the action in line with the personal status. [18]

$96 \%$ of the respondents admitted that they would think over their choice of translation work if there were some people objected it. And $95 \%$ said that the closer the relationship with the opposition was, the more considering they had. $67 \%$ of them would think of filial piety if the opposition was their parents, while $55 \%$ would connected their decision with the trust of friends, if the opposition was their friends. What does the data mean? The number of $96 \%$ reflects the strong desire of harmony pursuing in China. Everyone wants to have a good relationship with others and try to avoid the conflicts if possible. The number of $95 \%$ explains the degree of relationship decides how important people's opinion to certain person. Both filial piety and friend's trust can embody the interdependence in a society, which show the close dependence between children and parents, between persons and their friends according to relationship orientation. Interdependence in relationship can be discovered obviously from more than half of the respondents.

\section{About Authority Orientation}

Almost in all societies, some people are endowed with more power and authority than others in different levels, such as parents, teachers and managements. [19] As it is mentioned above, most of respondents would obey the ideas of authorities (boss, English teacher or the big-shot scholar) when choosing the translation work. About the reason, $83 \%$ agreed that the social relationship such as between employer and employee, between teacher and student, was considered seriously. $73 \%$ of them believed that their English teacher had the professional knowledge and experience of English translation, and could make more sensible decision. Talking about the big-shot scholar, $80 \%$ have 
the same idea. But only $16 \%$ of the respondents thought the reason may be that they worshiped the boss, English teacher or big-shot scholar.

These data gives us three facts and the first two facts show strong authority orientation of Chinese society. First, Chinese people are sensitive to the authorities. Boss, teacher and big-shot scholar all belong to the authorities to some degree. Most of the respondents realize the different social positions among people and obey the authorities' opinion consciously. The number of people think over the boss's opinion are more than the number of those think over the teacher's or scholar's opinion, probably for some realistic reasons, such as money, fierce competition in job hunting. Second, Chinese people are dependent on the authorities. More than $2 / 3$ of the respondents believe their English teacher or a big-shot scholar can make more sensible decisions in choosing the suitable work to translate, because they trust those people's professional ability and would like to be dependent on them. Third, nowadays, it is difficult to find out Chinese people's worship to the authorities, for less than $1 / 5$ of the respondents agree that their worship to others is the reason why they would obey others' ideas. This is a notable development trend which may connect with the development of science and technology and the social development in China. The development of science and technology make some unexplainable things in the past be solved. The unique social development in China let people put all humans in the same position. Both of them break down people's worship.

\section{About Others Orientation}

From the questionnaire, $96 \%$ of the respondents admitted that they would think over their choice of translation work if some people objected it. If all the people around were against their choice, $77 \%$ would give it up. There are three reasons that these people offered mainly. First, $67 \%$ confessed that they did not want to be strange or different with everyone else. Second, 63\% thought that their selection probably had some problems, thus all the people around would object it, and they did not want to make mistakes and be punished. Third, 57\% agreed that the selection of translation work was not a principal thing which was not worth insisting.

These data shows that people worries about others' impressions and ideas and do not want to be different, and that people hope to be correct all the time and try to keep their good reputation among the people around. Humans are in a web of social influence. Facing with others' objection, almost everyone thinks over and over before they do the final decision in the questionnaire. If it is necessary, they would like to change their behavior in order to meet the expectations of others. It is a kind of deference or conformity. Some psychologists offer two reasons why people conform others."Some probably conformed because they did not know what to do in a confusing or unusual situation....Other people probably conformed because they did not wish to be ridiculed or punished for being different from everybody else." [20] The two reasons can be discovered from the data above. In the investigation, the respondents show their obvious others orientation.

\section{Conclusions}

Four parts in Yang's social orientation theory, including family orientation, relationship orientation, authority orientation and others orientation, can be observed in the investigation about the choice of translation work. Most of the key points in each part are supported by the respondents. But there are still some notable exceptions. For 
example, people did not show their worship to authorities obviously. Although the samples here are limited and the questionnaire is not perfect, the author believes the reasons of the phenomenon need further study.

"Values guide the selection or evaluation of actions, policies, people, and events.",[21] Chinese value orientation guide translator's choice of translation work. When selecting the suitable work to translate, a translator considers not only his or her own opinion, but opinions from people around in the society, especially from families, friends and authorities. Chinese translators are incline to choose the translation work which are acceptable or benefit to the people in the same group such as a country, unless they have firm faith or specific purposes for the choices. So it is valuable to study questions from the point of Chinese social orientation, like why these authors', not those authors' work were translated into Chinese, why a translator chose the certain types of work to translate, etc.

\section{Acknowledgement}

This research was financially supported by the Education Department of Sichuan (16SB0129).

\section{References}

[1] Fei Xiaotong, Traditional Chinese Fertility System, Peking University Press, Beijing, 1998.(in Chinese)

[2] Qian $\mathrm{Mu}$, Chinese National Traits and Culture from Chinese History, The Chinese University Press, Hongkong, 1979.(in Chinese)

[3] Yu Yingshi, The Modern Significance of Chinese Culture from the Point of Value System. Times Culture Press, Taibei, 1984.(in Chinese)

[4] Weber, M., The Religion of China, Free Press, New York, 1964.

[5] Riesman, D., Some types of character and society, in: D. Riesman, The Lonely Crowd, Yale University Press, New Haven, 1952, pp. 1-50.

[6] Parson, T. \&White, W., The link between character and society, in: T. Parsons (Ed.), Social Structure and Personality, Free Press, New York, 1961, pp. 183-235.

[7] Hsu, F. L. K., Rugged Individualism Reconsidered: Essays in Psychological Anthropology, University of Tennessee, Knoxville, 1983.

[8] Triandis, H. C., Collectivism vs. individualism: a reconceptualization of a basic concept in cross-cultural psychology, in: G. K. Verma \& C. Bagley (Eds.), Cross-cultural Studies of Personality, Attitudes and Cognition, Macmillan, London, 1988.

[9] Triandis, H. C., Bontempo, R., Villareal, M. J., Asai, M., \& Lucca, N., Individualism vs. collectivism: cross-cultural perspectives on self-ingroup relationships, Journal of Personality and Social Psychology, 54,323-338. (1988)

[10] Yang. K. S., Chinese character and behavior: route and metamorphosis, Chinese Journal of Psychology, 23,39-57. (1981)

[11] Information on http://wenku.baidu.com/view/24494c300722192e4536f673.html 
[12]David Block, The Social Turn in Second Language Acquisition, Shanghai Foreign Language Education Press, Shanghai, 2016.

[13]Lucy Xing Lu \& Guoming CHEN, Language change and value orientations in Chinese culture, in: Steve J. Kulich, Liping Weng \& Michael H. Prosser (Eds.), Value dimensions and their contextual dynamics across cultures, Shanghai Foreign Language Education Press, Shanghai, 2014, pp. 285-304.

[14]Chen Qi, The influence of Chinese social Action orientation on a translator's culture translation, Journal of Sichuan University of Science \& Engineering (Social Sciences Edition), (2012) 65-68.(in Chinese)

[15]Liu Shuxian, The reconstruction of Chinese people's value in modern times, in: Shen Qingsong(Eds.), Chinese Values, China Renmin University Press, Beijing, 2013, pp. 189-217.(in Chinese)

[16] James Georgas \& John Berry, Family values across cultures, in: Steve J. Kulich, Liping Weng \& Michael H. Prosser (Eds.), Value dimensions and their contextual dynamics across cultures, Shanghai Foreign Language Education Press, Shanghai, 2014, pp. 133-164.

[17] Yu Wenli, The Values of the Chinese, China Renmin University Press, Beijing, 2012.(in Chinese)

[18]Hsu, F. L. K., Clan, Caste, and Club: A Comparative Study of Chinese, Hindu, and American Ways of Life, Van Nostrand, Princeton, N. J., 1963.

[19] Michael W. Eysenck, Psychology: An International Perspective, Psychology Press, London, 2004.

[20]Elliot Aronson, Timothy D. Wilson \& Robin M. Akert, Social Psychology, 7e., Beijing World Publishing Corporation, Beijing, 2012.

[21] Shalom H. Schwartz, Basic human values: their content and structure across cultures, in: Steve J. Kulich, Michael H. Prosser \& Liping Weng(Eds.), Value Frameworks at the Theoretical Crossroads of Culture, Shanghai Foreign Language Education Press, Shanghai, 2012, pp.257-294. 